\title{
Laparoscopy in non-traumatic emergency general surgery operations
}

\author{
Serdar Kırmızı
}

Department of Gastrointestinal Surgery, Yozgat City Hospital, Yozgat, Turkey

\begin{abstract}
Introduction: Laparoscopic surgery is currently a standard treatment procedure for many elective surgery cases. Laparoscopic surgery has been increasingly preferred in emergency general surgery operations. This study aims to investigate the importance of emergency laparoscopic surgery in a secondary hospital.

Materials and Methods: The study was conducted retrospectively at Yozgat City Hospital General Surgery Service between January 2018 and March 2020. Patients who underwent non-traumatic emergency surgery were included in the study. The cases who underwent laparoscopic surgery were determined.

Results: Of the 768 patients who underwent emergency surgery, 732 were non-traumatic cases. It was found that laparoscopic surgery was performed in $62.8 \%$ of appendectomy cases, $75 \%$ of cholecystectomies, $66.6 \%$ of diverting stoma operations, $8.3 \%$ of brid ileus cases, $11.1 \%$ of incarcerated/strangulated hernias and $11.1 \%$ of peptic ulcer perforations.

Conclusion: Laparoscopic surgery is more preferred in appendectomy, cholecystectomy, and diverting stoma operations. In order for other patient groups to benefit from the advantages of minimally invasive surgery, in the emergency laparoscopic surgical experience of surgeons should be increased during their residency.

Keywords: Acute abdomen; emergency laparoscopy; minimally invasive surgery; secondary hospital.
\end{abstract}

\section{Introduction}

Acute abdomen is a life-threatening condition that often requires urgent surgical intervention. It accounts for $11 \%$ of the general surgery operations carried out in the USA. Approximately, $50 \%$ of total mortality is seen in these cases. ${ }^{[1]}$ The traditional approach to treatment is laparotomy. Depending on the technical facilities of the hospital and the surgeon's experience, laparoscopic surgery is also a treatment option. Laparoscopy has been used for diagnostic purposes only for many years since the beginning of the twentieth century. ${ }^{[2]}$ Following the definition of laparoscopic appendectomy and cholecystectomy after the 1980s, it has been used by many surgeons for therapeutic purposes. ${ }^{[3-4]}$ Today, its use in esophagogastric, colorectal, hepato-pancreaticobiliary, bariatric, and metabolic surgery has gradually increased and has become the standard practice. Increasing experience in these areas and technological developments in the instruments used have encouraged surgeons to adopt laparoscopy in emergency surgery. The present study aimed to investigate the impor- 
tance of laparoscopic surgery in non-traumatic emergency general surgery in a secondary hospital.

\section{Materials and Methods}

The study was conducted retrospectively in the General Surgery Service of the Yozgat City Hospital between January 2018 and March 2020. From the hospital records, the data on the cases operated due to acute abdomen and stomatal openings due to Fournier gangrene were collected. Age, gender, the ASA (American Society of Anesthesiologists) value of the patients, and the performed operations were recorded. Informed consent was obtained from all patients in accordance with clinical and radiological pre-diagnoses. General anesthesia was applied in all laparoscopic cases. Pneumoperitoneum was provided using a Veres needle or by the open (Hasson) method, depending on the surgeon's preference. Intraabdominal pressure was kept in the range of 12-14 mm Hg. In open cases, general anesthesia or spinal anesthesia was applied. The operations were performed by six general surgeons and one gastroenterology surgery specialist working at different periods. Depending on the preliminary diagnosis, the surgeon took a position to face possible operation localization. Two trocars were used in fecal diversion surgeries. A diverting ileostomy was performed in patients with short sigmoid colon or in those who have obesity. In other operations, 3 or 4 trocars were used. The appendix stump was ligated with intracorporeal or endoloop ligature (Ethicon; Bridgewater, NJ, USA). The peptic ulcer perforation defect was repaired by primary or omentopexy using a 2-0 silk suture. TAPP (Trans-abdominal preperitoneal) repair was performed in laparoscopic inguinal hernias. Patients with strangulation underwent open surgery. The surgeon put a drain on the patients when needed.

Categorical values were expressed as frequency $(\mathrm{N})$ and percentage (\%) while parametric values were expressed as median, lower and upper values. In comparison, the Chi-square Test was used in categorical data and the Mann-Whitney U test was adopted since the parametric data did not show normal distribution. The difference was considered statistically significant if the P-value was 0.05 or lower in the $95 \%$ confidence interval. All data were analyzed using SPSS 22 (SPSS Inc., Chicago, IL, USA).

\section{Results}

Between January 2018 and March 2020, 2857 elective and emergency operations were performed in the Gen- eral Surgery service. Of the emergency cases, 36 were traumatic and 732 were non-traumatic acute abdominal cases. It was observed that laparoscopic surgery was used in more than half $(62.8 \%, 75 \%$, and $66.6 \%$ respectively) of appendectomy, cholecystectomy, and diverting stoma operations. While laparoscopic surgery was performed in $8.3 \%$ of brid ileus cases, it was observed that it was not applied in any tumoral obstructions and volvulus cases. It was determined that seven of the abdominal wall hernia cases underwent laparoscopic treatment. In three of these cases, open surgery was initiated due to small bowel segmental necrosis (Table 1).

Approximately $64 \%$ of the cases who underwent nontraumatic emergency surgery were laparoscopic appendectomy cases. It was found that laparoscopic appendectomy was preferred in young patients with a low ASA value ( $\mathrm{p}=0.001, \mathrm{p}=0.004$ respectively) (Table 2 ).

\section{Discussion}

The experience gained from elective laparoscopic surgery paved the way for laparoscopic operations to be applied in emergency cases and accordingly encouraged the surgeons. The use of laparoscopic surgery in the most common acute abdominal pathologies such as acute appendicitis, acute cholecystitis, ileus, and peptic ulcer perforation has increased significantly in the last decade. ${ }^{[5]}$ In the present study, it was found that laparoscopic surgery was preferred in most of the appendectomy, cholecystectomy, and fecal diversion operations in our secondary hospital. In the first consensus meeting held by the European Endoscopic Surgery Association in 2006, laparoscopic surgery was accepted as the standard treatment in cases of acute appendicitis and acute cholecystitis. ${ }^{[6]}$ Today, more than $90 \%$ of acute appendicitis is operated, and more than half $(51.2 \%)$ of these operations comprise laparoscopic appendectomy. ${ }^{[7]}$ The advantages of minimal invasive surgery such as decreased postoperative pain and hospital stay have been reported in laparoscopic appendectomy cases. ${ }^{[8]}$ The second most common reason for admitting to emergency departments after acute appendicitis is acute cholecystitis. ${ }^{[5]}$ The generally accepted approach was to perform early laparoscopic cholecystectomy within three days from the onset of symptoms in patients who are not at high risk for surgery. ${ }^{[9]}$ Since our hospital serves the rural population, patients usually admit to the emergency room at an advanced stage of cholecystitis. Therefore, with the exception of sac perforation and non-response to medical treatment, the general approach is the elective 
Table 1. Distribution of non-traumatic acute abdominal cases

\begin{tabular}{|c|c|c|c|c|}
\hline & $\begin{array}{c}\text { Open } \\
(n=419)\end{array}$ & $\begin{array}{l}\text { Laparoscopic } \\
\qquad(n=313)\end{array}$ & $\begin{array}{c}\text { Total } \\
(\mathrm{n}=732)\end{array}$ & $\begin{array}{l}\text { Laparoscopy } \\
\text { ratio (\%) }\end{array}$ \\
\hline Appendectomy & 174 & 294 & 468 & 62.8 \\
\hline Acute cholecystitis & 2 & 6 & 8 & 75 \\
\hline Brid ileus & 33 & 3 & 36 & 8.3 \\
\hline Ileus & & & 29 & 0 \\
\hline $\begin{array}{l}\text { Obstructive colon tumor (Hemicolectomy, } \\
\text { subtotal colectomy) }\end{array}$ & 22 & 0 & 22 & \\
\hline Unresectable obstructive colon tumor & $3^{*}$ & 0 & 3 & \\
\hline Volvulus & 4 & 0 & 4 & \\
\hline Incarcerated/strangulated hernias & & & 140 & 2.9 \\
\hline Inguinal & $69^{* *}$ & 2 & 71 & \\
\hline Femoral & 3 & 1 & 4 & \\
\hline Incisional & 34 & 1 & 35 & \\
\hline Umblical & 24 & 0 & 24 & \\
\hline Epigastric & 6 & 0 & 6 & \\
\hline GIS perforations & & & 36 & 11.1 \\
\hline Peptic ulcer & 27 & $4^{* \star *}$ & 31 & \\
\hline SI (meckel) diverticulum & 2 & 0 & 2 & \\
\hline $\begin{array}{l}\text { Large intestine (tumor or colon diverticulum } \\
\text { perforation) }\end{array}$ & 3 & 0 & 3 & \\
\hline Mesenteric ischemia & & & 12 & 0 \\
\hline SI segmental resection & 8 & 0 & 8 & \\
\hline Subtotal SI and colon resection & 4 & 0 & 4 & \\
\hline Fournier gangrene (ileostomy, colostomy) & 1 & 2 & 3 & 66.6 \\
\hline
\end{tabular}

SI: Small Intestine; ": One patient underwent Open Low anterior resection after Neoadjuvant CRT; **: Laparoscopy was initiated in three of the patients, however it was switched to open surgery due to small bowel necrosis; ${ }^{* * *}$ : Closed perforation was detected in one of the patients, aspiration and drainage was performed in this patient.

Table 2. Demographic and perioperative properties of appendectomy cases

\begin{tabular}{lccc} 
& Laparoscopic $(\mathbf{n = 2 9 4 )}$ & Open $(\mathbf{n = 1 7 4 )}$ & $\mathbf{p}$ \\
\hline Appendectomy & $110 / 184$ & & $0.47^{\star}$ \\
Sex (M/F) & $31(18-75)$ & $71 / 103$ & $0.004^{\star}$ \\
Age (years) & & $35.5(18-85)$ & $0.001^{*}$ \\
ASA & 232 & 114 & \\
I & 56 & 44 & $0.3^{*}$ \\
II & 5 & 15 & $0.001^{\&}$ \\
III & 1 & 1 & \\
IV & $60(25-120)$ & $136-125)$ & \\
Operation duration (minutes) & 294 & 38 & \\
Anesthesia type & 0 & & \\
General anesthesia & & & \\
Spinal anesthesia &
\end{tabular}


cholecystectomy after conservative treatment, rather than early cholecystectomy. This approach is also reflected in emergency cholecystectomy rates.

A vast majority of emergency cases requiring hospitalization consist of ileus patients. The main causes of ileus include postoperative adhesions, abdominal wall hernias (incarcerated or strangulated), malignancy, and volvulus. The traditional approach is to perform laparotomy in patients who do not respond to conservative treatment. Laparoscopic surgery is also a suitable option in selected cases. The success rate will increase when patients with single-band adhesion, low comorbidity, and with no perforation, diffuse peritonitis, and advanced abdominal distention are preferred. ${ }^{[10]}$ Otherwise, laparoscopic surgery increases intraoperative and postoperative complications. ${ }^{[11]}$ In our hospital, ventral and groin hernias comprised the most operated group of patients after appendectomy. In these cases, the general treatment approach was the laparotomy. The application of emergency laparoscopic treatment has not been clarified in incarcerated or strangulated hernias. ${ }^{[20]}$ The success of laparoscopic surgery in these patients depends on the surgeon's experience and suitable patient selection. ${ }^{[12]}$

Another important reason for the acute abdomen is peptic ulcer perforations (PUP). Of the cases, $49.4 \%$ form at the bulbous anterior wall, and the diameter of the perforation defect is generally less than $5 \mathrm{~mm} .{ }^{[13]}$ This indicates that approximately half of these patients are suitable for a simple laparoscopic suture without the need for extensive laparotomy incisions. Different operation techniques such as laparoscopic primary repair, omentopexy, or falsiformopexy have been described in the literature. ${ }^{[14]}$ In PUP, laparoscopic surgery has been shown to offer advantages such as reductions in post-operative comorbidity, mortality, hospital stay, and postoperative pain. ${ }^{[15]}$ In our hospital, primary repair or omentopexy repair has been performed depending on the surgeon's preference in the treatment of PUP.

Other than acute abdomen, perineal necrotizing fasciitis (Fournier gangrene) comprises the less common patient group of general surgery clinics that requires urgent intervention. Rapid and aggressive tissue debridement is the basic approach, however, fecal diversion is required in $25 \%$ of patients. ${ }^{[16]}$ The operation can be in the form of a loop ileostomy or loop colostomy, depending on the anatomical structure of the patient and the sigmoid colon. Considering that this patient group is obese and has high comorbidity, it is clear that opening a stoma with a minimal invasive method will provide an important advantage. In a retrospective study, the laparoscopic fecal diversion has been shown to reduce hospital stay and postoperative complications compared to laparotomy. ${ }^{[17]}$ In the present study, the cases consisted of patients with obesity and comorbidity, and one of the patients underwent ileostomy while another one underwent colostomy.

The limitations of the present study include a low number of patients, being a retrospective study, and some shortcomings in the perioperative data of the patients related to the fact that our hospital is a service hospital. However, the suitable facilities of the hospital for laparoscopic surgery had facilitated the realization of the study.

In our secondary service hospital, laparoscopic surgery is less preferred in emergency surgery operations other than acute appendicitis, acute cholecystitis, and diverting stoma. For this patient group to benefit from the advantages of minimal invasive surgery, the emergency laparoscopic experience of surgeons should be increased during their residency training.

\section{Disclosures}

Ethichs Committee Approval: Retrospective study.

Peer-review: Externally peer-reviewed.

Conflict of Interest: None declared.

\section{References}

1. Scott JW, Olufajo OA, Brat GA, Rose JA, Zogg CK, Haider AH, et al. Use of National Burden to Define Operative Emergency General Surgery. JAMA Surg 2016;151:e160480. [CrossRef]

2. Stellato TA. History of laparoscopic surgery. Surg Clin North Am 1992;72:997-1002. [CrossRef]

3. Semm K. Endoscopic appendectomy. Endoscopy 1983;15:59-64. [CrossRef]

4. Reynolds W Jr. The first laparoscopic cholecystectomy. JSLS 2001;5:89-94.

5. Arnold M, Elhage S, Schiffern L, Lauren Paton B, Ross SW, Matthews $B D$, et al. Use of minimally invasive surgery in emergency general surgery procedures. Surg Endosc 2020;34:2258-65. [CrossRef]

6. Sauerland S, Agresta F, Bergamaschi R, Borzellino G, Budzynski A, Champault G, et al. Laparoscopy for abdominal emergencies: evidence-based guidelines of the European Association for Endoscopic Surgery. Surg Endosc 2006;20:14-29. [CrossRef]

7. Sartelli M, Baiocchi GL, Di Saverio S, Ferrara F, Labricciosa FM, Ansaloni L, et al. Prospective Observational Study on 
acute Appendicitis Worldwide (POSAW). World J Emerg Surg 2018;13:19. [CrossRef]

8. Sohn M, Agha A, Bremer S, Lehmann KS, Bormann M, Hochrein $A$. Surgical management of acute appendicitis in adults: A review of current techniques. Int J Surg 2017;48:232-9.

9. Wakabayashi G, Iwashita Y, Hibi T, Takada T, Strasberg SM, Asbun HJ, et al. Tokyo Guidelines 2018: surgical management of acute cholecystitis: safe steps in laparoscopic cholecystectomy for acute cholecystitis (with videos). J Hepatobiliary Pancreat Sci 2018;25:73-86. [CrossRef]

10. Ten Broek RPG, Krielen P, Di Saverio S, Coccolini F, Biffl WL, Ansaloni $L$, et al. Bologna guidelines for diagnosis and management of adhesive small bowel obstruction (ASBO): 2017 update of the evidence-based guidelines from the world society of emergency surgery ASBO working group. World J Emerg Surg 2018;13:24. [CrossRef]

11. Quah GS, Eslick GD, Cox MR. Laparoscopic versus open surgery for adhesional small bowel obstruction: a systematic review and meta-analysis of case-control studies. Surg Endosc 2019;33:3209-17. [CrossRef]

12. Birindelli A, Sartelli M, Di Saverio S, Coccolini F, Ansaloni L, van Ramshorst GH, et al. 2017 update of the WSES guidelines for emergency repair of complicated abdominal wall hernias. World J Emerg Surg 2017;12:37. [CrossRef]

13. Varcus F, Paun I, Duta C, Dobrescu A, Frandes M, Tarta C. Laparoscopic repair of perforated peptic ulcer. Minerva Chir 2018;73:188-93.

14. Ölmez A, Çiçek E, Aydın C, Kaplan K, Kayaalp C. Omentopexy versus falciformopexy for peptic ulcer perforation. Ulus Travma Acil Cerrahi Derg 2019;25:580-4. [CrossRef]

15. Agaba EA, Klair T, Ikedilo O, Vemulapalli P. A 10-Year Review of Surgical Management of Complicated Peptic Ulcer Disease From a Single Center: Is Laparoscopic Approach the Future? Surg Laparosc Endosc Percutan Tech 2016;26:385-90.

16. Yılmazlar T, Işık Ö, Öztürk E, Özer A, Gülcü B, Ercan İ. Fournier's gangrene: review of 120 patients and predictors of mortality. Ulus Travma Acil Cerrahi Derg 2014;20:333-7. [CrossRef]

17. Gorgun E, Gezen FC, Aytac E, Stocchi L, Costedio MM, Remzi $\mathrm{FH}$. Laparoscopic versus open fecal diversion: does laparoscopy offer better outcomes in short term?. Tech Coloproctol 2015;19:293-300. [CrossRef] 